\title{
Vision, revelation, violence: Technology and expanded perception within photographic history
}

\section{Tom Slevin}

Published in: Philosophy of Photography. Volume 9, Number 1. 2018. Pp. $53-70$.

doi: 10.1386/pop.9.1.53_1

\begin{abstract}
This article considers photography's role as a visual technology and the consequent effects of expanded frames of knowledge. At the very moment human vision and memory were called into profound doubt, photography provided a mechanical, prosthetic extension to perceptual experience. However, as a technology, it contains the potential for both revelation and control. In this article, photography is considered as a technique that: expands human perception; inscribes its own mechanical operations into new visual forms, therefore enframing and encoding visible knowledge; and can be harnessed as a disciplinary instrument and technique of power. As a consequence, photography's revealing of hitherto invisible dimensions of reality unfolds within a history of revelation, spectacle and power.
\end{abstract}

\author{
Keywords \\ photography \\ technology \\ vision \\ Ori Gersht \\ power \\ Heidegger \\ control \\ modernity
}


Questions surrounding technology have constituted profoundly important issues in the twentieth and into the twenty-first centuries. Not the least of these, are issues concerning visual technology and the development of new forms of knowledge through revelation of matter that was once invisible. Technological prosthesis liberates and extends vision and knowledge that are otherwise limited to the terms of human embodiment. Photography occupies a crucial position in the historical and contemporary revelation of objects of knowledge that lie beyond the horizon of human perception. However, as a condition of its technicity, photography simultaneously harbours the potential for perceptual emancipation and the threat that it might act as a technique of power and disciplinary control. As such, this article will consider issues of the technological development and prosthetic deployment within photographic history, whereby the medium acts as a technique for revelation and a disciplinary instrument harnessed by institutional power. The article will go on to consider, in questioning photography's 'technological condition', Ori Gersht's Big Bang (2006) and Pomegranate (2006). Gersht's work considers not only the technological form of photography through revealing the unseen but also technology's relationship to perception, reality and history. This will lead to consideration of Gersht's work as self-reflexively referring to historical entwinement of revelation and destruction operating throughout photography. This reading of history incorporates Martin Heidegger's ([1953] 2003) warning of the danger and liberation resulting from the (ab)uses of technology but also from the structure and organization of the technology itself.

\section{Visual prosthesis and expanded perception}

Throughout the history of western culture, technologies of perception have been a foundational basis for the construction of visibility. However, the 'reality' produced is not a stable entity, but one that is constantly in the process of (re)definition by technical knowledge and its systems of representation. Photography provided a prosthetic extension to the experience of reality for both vision and memory by enhancing and expanding the scope of 
perception while inscribing that moment upon a fixed, two-dimensional surface. Photography also reveals and evidences elements of reality that would otherwise remain concealed. For example, Wilhelm Röntgen's X-ray at the end of the nineteenth century allowed a hitherto concealed dimension of perception to become visible. His wife, Bertha Röntgen, reportedly remarked upon seeing the photo-graph: 'I have seen my own death!'. As a nineteenth-century visual technology, providing new forms of representation and knowledge, the X-ray passed opaque objects and opened up the possibility of unrestricted, penetrating vision. Tim Armstrong writes,

The body could be penetrated by a barrage of devices: the stethoscope, opthalmoscope, laryngoscope, speculum, high-intensity light, X-rays. Its physiological rhythms could be followed

55

in the pulse, temperature, and respiration chart; its blood pressure monitored; its bacteria examined by powerful microscopes [...]. The body was resolved into a complex of different biomechanical systems, conceived in thermodynamic terms. (1998: 2)

Nineteenth-century modernity interrogated visible reality through often intrusive and intense techniques. 'Reality' itself transformed, becoming relative to the technological operation and form it gave to the (in)visible world.

Figure 1: Wilhelm Röntgen, X-ray print of his wife, Anna Berthe Röntgen's hand, 1896.

New photographic technologies emerged at the historical moment when both human perception and memory were called into profound doubt. Indeed, more broadly, and in 
different ways, Michel Foucault ([1966] 2007) and Jonathan Crary (1990) both identify a radical shift in western thinking in the nineteenth century. They propose that the notion of reality as something visible and transparent, and knowledge something that could be extracted through an objective operation upon a stable world, was overturned. Instead, this conception was replaced by recognition of a much more relative, energistic and fluxive reality. For example, Henri Poincaré wrote, 'our perception of space is the product of an internal coordination of our various sensory faculties into a spatial gestalt we mistakenly identify as external to us' (Henderson 1983: 82-89). In other words, the human relation to an exterior reality is a constructed perception based upon the terms and condition of our embodiment. Technology further refines the process of extricating objects of knowledge from its environment. Photography's apparent indexicality arrived in a moment whereby that very issue of transparency between reality and representation was in the process of being overturned. David Bate has considered how memory (and we might add practices of looking) in this period instituted new processes of stability and control: 'a whole new era of the industrialization of public memory as "commemoration" [...] the invention of museums, civic libraries and public institutions has been developed as archives for memory' (2010: 246).

In The Order of Things, Foucault outlined the shift within Modernity from a Renaissance model of knowledge, whereby the signifier and signified was 'a uniform and unbroken entity in which things could be reflected one by one, as in a mirror, and so express their particular truths' ([1966] 2007: 38). He described a 'non-distinction between what is seen and what is read, between observation and relation' ([1966] 2007: 43). In the moment of photography's emergence, this signifier-signified relation had been dismantled as a process of knowledge since the relationship between form and content was under interrogation. As Foucault ([1966] 2007) and Crary (1990) both argue, 'reality' could no longer be conceived as a stable entity as it was under constant investigation and redefinition in and through technical knowledge and its systems of representation. Prior concepts of a stable field was displaced by the revelation of multiple, simultaneous fields of reality. 
Nineteenth-century research into the fallibility of human vision, concurrent with the emergence of photography, is exemplary of this disturbance in knowledge and representation. Not only was, as

56

Jonathan Crary writes, 'the eye itself [...] a field of statistical information' (1990: 104), but the nature of light was also being uncovered. From Alberti's account of Renaissance vision to the theories of Isaac Newton, it had been believed that direct geometric visual 'rays' were either emitted from, or entered into, the observer's retina. This belief initially appeared to be confirmed by the camera obscura. Developing scientific techniques rapidly transformed beliefs about the world. For example, in terms of vision, the very constitution of light itself was replaced by a very different, electromagnetic, knowledge. Augustin Jean Fresnel's demonstrations of transverse light vibration and refraction and James Clerk Maxwell's discoveries in electric and magnetic fields, published in his 1865 A Dynamical Theory of the Electromagnetic Field, showed that light was constituted by waves, not linear rays. Light itself was revealed as continuous and oscillating, rather than geometric and linear. It now belonged to a spectrum that could enlighten different aspects of an electromagnetic world. However, just as light itself was found to be mobile, so too was human sensation. For example, Johannes Müller chemically and electrically manipulated bodily sensation to prove that perceptual experience was not purely created from a stable external 'reality'. J. W. Goethe and Arthur Schopenhauer both revealed how the human body produced sensation in the absence of stimuli through their research into colour, leading to ideas of the human subject as the active creator of its experience. The body itself was reconsidered as a technical system for constructing and encoding reality relative to its processes and limitations.

Figure 2: Ernst Mach, shadowgraph of a bullet's supersonic flow, 1887. 
Ernst Mach's 1887 image depicting a bullet's generation of supersonic waves is an important demonstration of technological modernity's processes of unconcealment. However, (as we shall also see in Ori Gersht's work) it also draws attention to its own operations of representation. The 'shadowgraph' - created as light passed through disturbed airflow reflecting on to a film plate, with the white vertical lines indexical to the camera shutter trip wires - captured supersonic waves. Mach's research demonstrates the modern idea that time and space were relative to bodies in motion. Essentially, it was revealed that there was a simultaneous relation between an object and its space; a body does not simply exist as an object in time and space, but is in dynamic relation to it. Mach's work belonged in a historical and cultural moment that rejected prior Euclidean and Newtonian models of space and time. Instead, despite photography's own limitations, it could nevertheless provide visual evidence for the replacement of 'absolute' models of reality and 'stable' concepts of space-time with ideas of fluidity, fluxive fields of energy, waves and motion. Within the modern episteme, objects and bodies became re-imagined as energy, whose force was compressible, manipulable and made dynamic. Reflecting Poincaré's ideas, Mach also articulates how reality is dependent upon the structure of the operation upon it:

In mentally separating a body from the changeable environment in which it moves, what we really do is to extricate a group of sensations on which our thoughts are fastened and which is

57

of relatively greater stability than the others, from the stream of all our sensations $[\ldots]$ bodies or things are compendious mental symbols for groups of sensations symbols that do not exist outside thought. ([1882] 1968: 180)

For the modernist avant-garde, technological revelations about the ontology of reality provided inspiration for the artistic representation of form and content - converging 
contemporaneous ideas within art, science, literature and philosophy. Cubism and Futurism, amongst others, were inspired by the modern notions that matter fundamentally lay in nonEuclidean geometries, n-dimensions, simultaneity, dynamism and relativity. Their works are only perceived as 'abstract' in relation to existing figurative convention. The avant-garde considered that they were responding to new, modern 'truths' and therefore more veridical than representation through static perspective. For example, Mach's photographs of supersonic waves are reproduced in the dynamic 'force lines' structuring Futurist painting (such as Gino Severini's painting The Revolt of 1911), itself influenced by Henri Bergson's philosophy of dynamism. Indeed, Futurism perhaps most directly incorporated the technological revealing of a reality constituted by energy, flow and dynamism.

Lucy Adelman and Michael Compton (1980) write that modern artists were fascinated with the limits of perception and the possibility of 'non-Euclidean' and ' $n$-dimensional' reality. Similarly, John Gage (1980) notes that the late nineteenth-century rise in idealist philosophy was related to artistic claims for the existence of a 'higher', four-dimensional reality. Linda Dalrymple Henderson (1983) remarks the prevalence of $n$-dimensional concepts within literature that gained popular currency within the cultural imagination. It is within these contexts that the photographic representation of concealed dimensions of reality in the images of Mach and Röntgen appeared. From Eadweard Muybridge's photographic studies of a horse's gallop, to pseudo-scientific 'spirit' photography, photography was a form of visual technology that depicted actual and fantastical dimensions of reality with the force of evidence. One might compare Röntgen's and Adrien Majewski's photography of female hands to understand how these superficially similar images - Röntgen's hand is indexical as an X-ray while Majewski's image makes claims around the indexicality of spiritual 'effluvia' exist within the same cultural moment.

Figure 3: Adrien Majewski, Hand of Miss Majewski (digital effluvia), c. 1898, silver gelatin print, $19.37 \mathrm{~cm} \times 14.13 \mathrm{~cm}$. SFMOMA. 


\section{Technology: Simultaneous revealing and concealing}

In the moment of photography's emergence, its technological potential was harnessed according to the desires of its operators and audiences. As a visual technology, the limits of its representation, how, and by whom, this was used, were being determined. In 'The question concerning technology' ([1953] 2003), Martin Heidegger proposed that technology is the condition upon which reality is revealed

58

through representation. He described this as the 'bringing-forth' of matter into the presence of appearance. Truths derived from technics are based upon 'unconcealing' the potential of that which was hitherto concealed. In other words, technology structures representations of reality through operations of 'revealing' (das Entbergen). Heidegger suggested that technology's relation to revealing and truth has had a long cultural inscription; the Ancient Greek word for truth through process was 'alethia' - a word that also meant 'revealing'. The Roman translation of this was 'veritas', further weaving together concepts of 'revealing' with 'truth'. Heidegger wrote, 'Technology is a mode of revealing. Technology comes to presence in the realm where revealing and unconcealment take place, where alethia, truth, happens' ([1953] 2003: 255). However, this 'revealing' must follow a process, a mode, or technique, since it is dependent upon the structure and limitations of the operation to both unconceal and signify. The very organization of the technological unconcealing therefore organizes 'reality'; technology structures reality's unconcealment, and consequently, a 'truth' is revealed. Heidegger referred to these structures upon which reality is premised as Gestell (enframing). Therefore, we might propose that technology is a revealing of the world but simultaneously conceals it, as the operation is encoded by the very process of unconcealment. Technology is a technique for both 'revealing' and 'enframing'. 
The photographic inscription of a spirit amongst the living, the galloping hooves of a horse, or a bullet passing through air, are all dependent upon photography's presumed technological ability to indexically encase the transient and temporal into a spatial representational order. However, space and time are profoundly different orders as the photographic lens replicates a classical, perspectival model, a testimony of presence through the permanence of its trace. As mentioned, the camera functioned as prosthesis, acting as a guarantor against the doubts raised against the limits of human vision. However, for JeanFrançois Lyotard ([1988] 1991), the mechanical 'truth' of photography provided culture with the cybernetic embodiment of perspective through the camera. Bate has described photography as 'internalized prosthetic devices for memory' that has a complex entanglement with 'natural memory' (2010: 251). However, for Lyotard, the camera cannot reconstitute the experiential continuity of embodied perception, but instead reproduces a disembodied and, for that matter, genderless representation. As the mechanical replication of perspective, the camera might therefore be seen to embody the same prior critiques of mathematics and geometry from thinkers such as Kant to Edmund Husserl. For example, Leonardo da Vinci realized perspective's failure to incorporate the embodied terms of perception such as stereopsis (from the Greek stereo - solidity, opsis - vision, suggesting the 'solidity' of vision is actually derived from more than one viewpoint). Other problems included the transformation of perspective through colour relativity, psychology and the temporality of matter such as smoke or water. Perspective fundamentally transforms matter without a singular, identifiable fixed moment in space through its representational structure and spatial organization.

59

Heidegger's debt to Husserl is evident regarding the enframing inherent in technology. Husserl's Origin of Geometry ([1936] 1989) critiqued the encoding of the experience of space and time into geometric models. His work appears particularly motivated by a concern with the transparency and lack of criticality afforded to geometric perspective as a self-evident and transparent process of representation. Husserl describes this as an imposed construction that reordered perception, yet became indexical for 'objective' vision, 
gaining 'ontic validity' ([1936] 1989: 167). But, for Husserl, though imposing itself as the indeterminate horizon of all possible knowledge, the totality of reality cannot be known. Knowledge issues out of the particular structures of representation - a Husserlian insight that Heidegger makes emphatic by articulating it conceptually as a process of translation through encoding and enframing that works via technical processes.

One example of concerns raised against the technological structure of enframing vision lies with the Italian Futurists. They had initially been intrigued by photography's potential for expanded vision and revealing concealed dimensions of existence. Photographic experiments attempted to harness experimental science and aesthetics. As Giovanni Lista observes, two contemporaneous photography journals, II Dilettante di fotographia and II Progresso fotographico, published articles on parascientific experiments (such as Hippolyte Baraduc and Louis Darget's 'photography of thought'), spirit photography and 'ectoplasmic' images. These featured alongside Röntgen's work, Mach's 'dynamography' and Marey's chronophotography. The Futurist photographic pioneers Anton Giulio Bragaglia and Gustavo Bonaventura believed photography could align with the aims of Futurist painting, 'to materialize and give form to what up to now has been considered ethereal, inflexible, unmodifiable and invisible' (Lista 2001: 28).

While the Futurists were interested in photography's potential for expanding dimensions of perception, they experienced frustration with the specific structure of the camera's apparent replication of a pre-modern, static representational structure. The process of unconcealing was therefore enframed by the very structure of the visual technology. To put it another way, photography mechanically reproduced a classical visual structure for reordering perceptual experience. The Futurist movement eventually rejected photography as a medium due to its encoding of a temporal, dynamic, fluxive modern world into what they came to see as fixed classical forms of stasis and permanence. They condemned precisely what Lista describes as photography's 'technological determinism' (2001: 27). 
Inspired by the ideas and writings of the Henri Bergson, and particularly his notion of dynamic, temporal 'becoming', the Futurists came to regard the photographic image as 'the petrification of life, or as actually the very negation of the sensation of life [...] arbitrarily stopping time and destroying the energistic dimension of the act' (Lista 2001: 10). Their attitude towards photography as a 'rigor mortis' and 'mortification' is explained through photography's condition as 'a medium that was ontologically hostile to any dynamic perception of reality as absolute "becoming"' (Lista 2001: 10). In an age bearing witness to the technological transformation of human experience, from industrial

60

modernity's prosthetic extrapolation of the body in space and time (the bicycle, automobile and then airplane), or in the extension of its nervous system (the telegraph and telephone), photography provided a prosthesis for memory through the mechanical rematerialization of a moment fixed upon a surface.

\section{Vision/violence}

Despite the Italian Futurist's rejection of photography, they were nevertheless fascinated by its technological capacity for revelation. Mach's pioneering photographic studies were clearly of interest, particularly his principal contribution of research on ballistics and shock waves, even though his name is most commonly associated with aerodynamics. The two are intimately related since the characteristics of supersonic flow anticipated research that became fundamental to the development of airplanes. Indeed, Mach's research on these forces was still being understood after the Second World War. Essentially, his techniques of unconcealment provided possibilities for the subsequent development of air flight and a new, 'omniscient' horizon of perception. 
F. T. Marinetti famously celebrated what he perceived as the potential of technologically expanded vision harnessed to violence and domination. Paul Virilio notes that Marinetti 'was beginning to join together war, aviation and a vision which, in its fleeting aerial perspective, might be called "dromoscopic"' ([1984] 1989: 22). Virilio argues that technological modernity is premised upon a logic of speed (the Greek 'dromos' for 'to race'). For Marinetti, technology was essential to realize his Nietzsche-inspired idea of transcending the human. Marinetti's fusion of 'war, aviation and vision' - which arguably characterized the later trajectory of twentieth-century technology - was inspired by the scientific, industrial, technological, colonial and philosophical transformations within western modernity. Marinetti, more specifically influenced by Nietzsche's concepts of Übermensch and Wille zur Macht (widely disseminated in Italy in the years preceding the First World War) (Berghaus 1995), and Bergson's philosophy of 'creative evolution', believed that dromology would hurl humanity into the future, sweeping away classical regimes of time and space.

Technology could therefore become an instrument of human will. Marinetti saw in the epoch of industrial mechanization the possibility of a new Futurist man whose body could be supplemented, augmented and extended by the machine in a technologically facilitated process of evolution. Cinema and aviation were forms of expanded perception that Marinetti sought to harness to this omniscient 'new man'. Virilio proposes that cinema and aviation were 'becoming one way, or perhaps even the ultimate way, of seeing' ([1984] 1989: 17, original emphasis). As is often noted, Marinetti experienced his first flight in 1910, and in October 1911 witnessed Italian military airplanes being used for reconnaissance in the Turkish Italian conflict over North Africa. The following month, for the first time in the history of warfare, the air force was deployed in dropping explosives. Travelling to

Libya as a war correspondent, he celebrated the act as 'the most beautiful aesthetic spectacle of my life' (Virilio [1984] 1989: 73). The expanded perception offered by technology came at the price of novel forces of domination. 
One might summarize, following Virilio, that vision has superseded, or at least rivalled, explosives and ballistics as the principal instrument of military power. The ability to reveal the target through imaging technologies became more important than the destructive potential upon that image; revelation is the precondition for intervention. The ability to reveal, to make visible through technologies of what Heidegger calls 'presencing', became entwined with those of destruction. Yet again, it was in the nineteenth century that the unconcealment of (in)visible dimensions of reality mutated warfare into the tension between revealing and concealing. For example, the British army in India temporarily changed their uniform from white to khaki (Urdu for 'dust') to conceal the body within the environment. Through crypsis, the body became dust. The harmonization between figure and ground transformed warfare, and modernist painters were soon employed in the First World War camouflage units. Gertrude Stein famously wrote that Picasso, upon seeing a camouflaged vehicle, said, 'yes it is we who made it [camouflage], that is cubism' (1970: 18, original emphasis).

The relation between visibility and power occurs throughout photography. For example, while Nadar pioneered the first aerial photograph in 1858 aboard his balloon Le Géant ('The Giant'), this technique was quickly adapted by the military as reconnaissance (French 'recognition'). Although Italy had first deployed aerial bombardment in 1911, this was only less than a decade after the Wright brothers' first test flights of sustained and controlled air flight, and only five years after the first unassisted flight by Santos-Dumont in 1906. However, the imagination of aerial - omniscient - perception had already been begun in the US civil war through the development of hybrid camera-aircrafts from camera-kites, camerapigeons and camera-balloons. In the First World War, anti-aircraft artillery was designed to prevent air surveillance, and guns became synergistic with lighting. Revealing and destroying became increasingly synonymous while techniques of concealment mirrored developments in technologies of unconcealment. 
Figure 4: Honoré Daumier, 'Nadar elevating Photography to the high level of Art', Le Boulevard, 1863. Lithograph from Le Boulevard (25 May 1863). George Eastman Museum.

Figure 5: Nadar, aerial view of Paris, 1868, Wet collodian plate. Brown University Library.

As the camera (and later other media) complemented weaponry, Virilio notes a concurrent 'symptomatic shift in target-location and a growing derealization of military engagement. For industrialized warfare, where the representation of events outstripped the presentation of facts, the image was starting to gain sway over the object, time over space' ([1984] 1989: 1). After the Second World War, spy-satellites, drones and video-missiles became part of a strategy for 'global vision'. Military superiority became premised upon the instantaneity of sensors, interceptors and detectors rather than explosives. Physical warfare was increasingly divorced from tactical warfare as optical information and visual representation - provided by instruments such as thermal cameras and radar technology further yielded dimensions of reality that could be made visible for knowledge. Reality is fractured into information produced by visual instrumentation. Western militaries find guerrilla

62

warfare particularly frustrating since the omniscience of 'astral perception' over a visible target is refused. However, corporeality itself is less important than its image and the traces of the body re-revealed through sonar, infra-red and thermographic 'vision'. In this way, sound and heat become visual. Indeed, wars are fought upon the image as the product of technological and industrial prostheticization of human perception. Warfare and optics have an entwined history as vision is the precondition for violence.

\section{Expanded vision as power}


Within technology's 'emancipation' of reality through expanded perception lies its potential as a mechanism of power. This view of photography's history reflects Giorgio Agamben's concerns about political history:

It is almost as if, starting from a certain point, every decisive political event were double-sided: the spaces, the liberties, and the rights won by individuals in their conflicts with central powers always simultaneously prepared a tacit but increasing inscription of individuals' lives within the state order, thus offering a new and more dreadful foundation for the very sovereign power from which they wanted to liberate themselves. (1995: 121)

Heidegger argued that the origin of technology lay in techne, in the craft of unconcealing. It operates within a culture whereby nature is conceived as economy, as matter stored ('standing-reserve') for industrial and capitalist exploitation - the powers that, on the basis of the above, Agamben might argue make technology a disciplinary instrument. For Heidegger, this attitude appeared with the rise of modern physics and the reduction of matter to calculable values: 'The essential unfolding of technology threatens revealing, threatens it with the possibility that all revealing will be consumed in ordering and that everything will present itself only in the unconcealment of standing-reserve' (1953: 263). Following this, our concern might be that when both technology and matter are conceived in terms of resource and consumption, so emancipated forms of reality becomes the domain of power, control and exploitation. We might refer back to Mach's investigation into projectiles, shock waves and supersonic speeds that have been utilized by the military and consumer capitalism. Or we could also recall how, as has often been noted, Eadweard Muybridge's pioneering photographic experiments are reflected in Frank and Lillian Gilbreth's employment of photography in the science of motion study. Proceeding from the Taylorist field of scientific management, they documented, reorganized and disciplined the body of the industrial worker for increased efficiency and productivity. Étienne-Jules Marey's chronophotographic experiments, while capable of producing extraordinary images of astonishing beauty, were also employed by the French military to analyse and discipline the bodily rhythms of its 
soldiers. Photography provides the technique for studying the human body as an economic resource, and there is critical value, I argue, in thinking of this through Heidegger's notion of 'standing reserve'. Virilio notes, by placing chronophotography at the service of military research into movement, Marey 'was making the body disappear into a momentary agglomeration of sense-data' ([1984] 1989: 14).

63

Photography's revelations can, then, also be understood within a wider regime of 'biopower' that extended over the body of the population in the nineteenth century, in which period, as Foucault has remarked, 'there was an explosion of numerous and diverse techniques for achieving the subjugation of bodies and the control of populations, marking the beginning of an era of "bio-power"' (Foucault [1976] 1990: 140). Where nineteenth-century liberalism sought to harness technology for the improved regulation of the population, this dispersed matrix of power inscribed upon the body also became the basis for which reactionary politics attained greater disciplinary control. Foucault wrote, further: 'For the first time in history, no doubt, biological existence was reflected in political existence' ([1976] 1990: 142). The body became a statistical field of knowledge. Techniques and technologies of vision were instrumental to this process. However, these liberal interventions became the very condition for the harnessing of biological practices to reactionary politics after the First World War. Photography is complicit in this history of biopolitics. Indeed, this is well-discussed in histories of photography. As an instrument of ideology, John Tagg writes, 'Photography as such has no identity. Its status as a technology varies with the power relations which invest it [...]. Its nature as a practice depends on the institutions and agents which define it and set it to work' ([1984] 1988: 63). Geoffrey Batchen reflects on Tagg's claim: 'the meanings and values of any individual photograph continue to be entirely determined by its relationship to other, more powerful, social practices' ([1997] 1999: 6).

However, (photographic) technology is not ontologically destructive, even if it mechanically embodies a particular form of visual encoding. Its potential for beauty, 
emancipation, discipline and power is dependent upon its cultural and political uses. If expanded vision is aligned to increased 'truth', this clearly contains the ideological possibilities for beauty and violence. We might consider the more recent relationship between expanded perception and disciplinary mechanism in Harold Edgerton's pioneering work at MIT. The images that Edgerton made with Gjon Mili using stroboscopic equipment created beautiful, lyrical, flowing movements tracing temporal rhythm. However, Edgerton also photographed what we might call the 'explosive' moment of photography.

Edgerton's stroboscopic technique allowed for the unconcealment of phenomena inherent in the temporal minutiae beyond human perception. This ranged from the eruption of a drop of liquid to a nuclear explosion. Edgerton's photography is profoundly revelatory of the explosive instant and embodies the relationship between destruction and the spectacle produced. Indeed, as with conventional notions of the 'sublime', it is possible to perceive the entanglement of beauty and violence as

64

forms of power. In fact, Edgerton worked almost seamlessly between the entertainment and the military industries - those of spectacle and destruction - with his first book Flash! Seeing the Unseen by Ultra High Speed Photography (1939), his collaboration with Mili, working for MGM studios and being employed by the US military. His company EG\&G was contracted by the Atomic Energy Commission, and through Edgerton's development of the Rapatronic camera, the company provided the photographic record of the US's nuclear testing. At a distance of seven miles, with a ten-foot lens and a shutter speed of $1 / 100,000,000$ of a second (Marschall 1988: 135), Edgerton's images of nuclear eruption are technologically sublime through the arrest of a moment that is massively powerful, historic and terrible.

Ori Gersht (2007) directly references the fundamental importance of Edgerton's technological expansion of perceptual temporality. This history of the aesthetic convergence of violence and beauty, of photography's liberation of knowledge while also providing the 
means for greater power and as a disciplinary mechanism - that we have traced through examples such as Mach to Edgerton via Marinetti - is important to Gersht's work. Indeed, he locates his own practice within this history. For instance, his choice of camera participates with this reading of history. The Hasselblad camera enabled Gersht to photograph Big Bang (2006), Pomegranate (2007) and the series Time after Time: Exploding Flowers and Other Matters (2007). The camera's own history reflects the entwined history of vision, power and destruction. For example, in the Second World War, the Swedish government requested that Victor Hasselblad reconstruct a camera based upon a captured German aerial surveillance camera. Between 1940 and 1945, Hasselblad constructed an improved HK 7 camera for the military through its visual and aerial scope, negative size and adaptability to permanent aircraft mounting. In 1962, NASA employed Hasselblad cameras for space flight, for which they imaged the first Apollo moon landing. Hasselblad cameras (specifically the H4D-50) continue to be ordered by the US Defence Department's National Geospatial-Intelligence Agency, whose title alone indicates how the greater optical omniscience of space is crucial to national defence. Gersht's employment of expanded temporality therefore reflects the military's own deployment of digital high-speed cameras. For example, America's largest known military installation, the White Sands Missile Range - the nuclear testing site for the first atomic bomb on July 161945 that Edgerton documented - is still a missile-testing site. However, it has transformed according to a focus upon global optics provided by satellite information, using high-speed photography to observe flight and missile dynamics. As Virlio might propose, in a dromological age, speed is domination.

It is therefore within such a history of visual technology that we locate Gersht's Pomegranate and Exploding Flowers. However, his other bodies of work provide a context for the themes articulated. Indeed, Gersht has been consistently preoccupied with the tension inherent between vision and violence. For example, in Afterwars (1998) he photographed the ruptured, traumatized surfaces of 
Sarajevo's architecture after western media's evacuation of interest. The walls bear witness to the city as a site of conflict through the scars of bullets. Gersht himself reveals that as an Israeli he feels an emotional affinity with ethnic conflict. However, the historical importance of symbolism is perhaps no more important than it is in White Noise (1999-2000) whereby Gersht photographed the Polish countryside from the once-terrible train journey between Krakow and Auschwitz. He had a direct personal relation to this work as his father-in-law was one of Kosov's few survivors, having hidden with his father and brother after it was declared 'Judenrein' in 1942. However, in Gersht's concern with the limits of representation, the images became less about revealing than concealing and the recourse photography has to metaphor when attempting to represent ideas that its technological structure cannot bear as witness.

Therefore, how are memory and history communicated since the representation of witness inherently contains elements of interpretation, narrative and fiction? White Noise is sensitive to these problems in its 'liquidation' of the possibility of photographic representation. Both the subject and process Gersht uses create a photographic ambiguity, lying on the borderline between remembrance and forgetting, between presence and absence.

Challenging the western conflation of light with truth, the image itself passes through revealing into concealment: the image is paradoxically so exposed that it is emptied. Siegfried Kracauer's words in 1927, before his own escape from Nazi persecution, resonate here: 'In a photograph a person's history is buried as if under a layer of snow' ([1927a] 1993: 426).

White Noise addressed photography's capacity for revelation and concealment while Knowledge Factories (1999-2001) remains within modernity's shadow as he documented the architectural modularity of schools constructed after the Second World War. Evidently, he is drawn by the aesthetics of the modernist grid that were also employed in the construction of Sarajevo's tower blocks. While Gersht's modular architectures directly reflect the conservative aesthetics of Le Corbusier (and to some extent Mondrian), Mass Culture (2000-01) also embodies the docility and organization of the masses that Kracauer had warned might be exploited by authoritarian and capitalist forces ([1927b] 1995). Through spectacle, Kracauer 
perceived the complete rationalization and of bodily management inherent in capitalism and politics. Although Joanna Lowry has proposed that Gersht's images are a 'playful [...] engagement with a culture of leisure, rather than with the traumas of war' (2002: 63), we might also consider the inherent continuities between Gersht's work through an engagement with the legacy of modernity. Kracauer observed that the organized spectacle displayed the 'monstrous' ([1927b] 1995: 78) construction of modernity's aestheticization and politicization of dehumanized organization and rationalized control of its population. Indeed, for Kracauer, this was soon to be a feature of Nazi Germany. Therefore, we should perhaps rather consider Mass Culture to be part of Gersht's engagement with modernity and historically related to the trauma of war.

66

In Gersht's more recent work, there is a continued concern with photography's condition as a representational technology and with the theme of violence and beauty. Indeed, technology comes to the fore, almost as the object on display as form moves towards being content. The bullet within Gersht's Pomegranate (2006) recalls the revelation and destruction, embodied through the bullet, in the history of photography from Mach to Edgerton. It reveals both the enchantment and destruction inherent in the temporal expansion of the explosive moment. Referencing Juan Sanchez Cotán's Quince, Cabbage, Melon and Cucumber (1602), Gersht's lighting, spatial arrangement and framing are deliberately harmonious and seductive. Referencing Cotán's sixteenth- and seventeenth-century bodegónes in both their symbolic composition and naturalistic form, Gersht creates a technological ambiguity between painting and photography; the resolution of the ballistic collision maintains the seduction. At 1600 frames per second, the projectile enters from the right of the screen and impacts upon the pomegranate. Through the energy transfer between the two states, the titular subject is eviscerated. Gersht describes the specific use of this fruit because of its interior resemblance to human viscera - it bleeds through an 'act of extreme violence' (2007). 
Figure 6: Ori Gersht, Pomegranate, 2006. Still from digital film. The Jewish Museum, New York. Courtesy of the artist.

We should, however, also remember that the still life has a rich symbolic and allegorical tradition. For Gersht, as a Jewish artist, the pomegranate itself contains a cluster of meanings. It is one of seven plants representing the fertility of Israeli land; it is also believed to contain a seed for each of 613 commandments in the Five Books of Moses. Perhaps most revealingly, the Hebrew word for pomegranate is a homonymic of both 'ornament' and 'handgrenade'. Strikingly, therefore, the rhetorical overlap of beauty and violence directly incorporates both the history and meaning of the work itself: symbolism is encrypted within the piece, layered like a fruit itself. It is as Gersht has written, 'This tension is enhanced by the fruitful collision of the age-old need to capture "reality" and the potential of photography to question what it actually means' (Gersht 2007-08).

Figure 7: Juan Sanchez Cotán, Quince, Cabbage, Melon and Cucumber, 1602, oil on canvas, $68.9 \mathrm{~cm} \times 84.5 \mathrm{~cm}$. San Diego Museum of Art.

As the bullet penetrates the pomegranate's flesh, so Gersht describes the flowers within Time After Time (2007) and Big Bang (2006) as 'victims of brutal terror, revealing an uneasy beauty in destruction' (2007-08). These symbols of love, peace and tranquillity are made further fragile, having been frozen by liquid nitrogen to below 200 degrees to emphasize their frailty. If photography is a freezing of time, Gersht draws attention to this double-freezing within the nature-morte. Small explosive devices concealed within the still-life detonate, shattering the flowers. Their fragmentation is photographed at $1 / 3200$ of a second. One might recall Walter Benjamin's reflections upon humanity in its age of seemingly unlimited destructive power in the First World War: 'never has experience been contradicted more thoroughly $[\ldots]$ beneath these clouds a field of force of destructive torrents and explosions, was the tiny, fragile human body' ([1936] 1977: 84). Indeed, the piercing 
soundtrack to Gersht's film Big Bang II (2006), a combination of Israeli air raid and Holocaust memorial sirens obtained from sound libraries, acknowledges the consequences of visual technologies upon human suffering.

Figure 8: Ori Gersht, Blow Up: Untitled 5, 2007, Lightjet print mounted on aluminium, $248 \times 188 \mathrm{~cm} \times 6 \mathrm{~cm}$ (framed). Mummery \& Schnelle Gallery, London. Courtesy of the artist.

67

Gersht's work considers the interrelation between expanded technological perception, the object of warfare and the evisceration of flesh and matter within an aesthetic experience. He describes the affect produced by this a 'hypnotic, meditative experience' (2007). It reflects a complex relation between violence and beauty, whereby violence is disguised, or even justified, by beauty. Indeed, one may unfold from, or envelop, the other - particularly within a notion of the sublime in the production of awe. This reflects the technological history of photographic revealing and how vision has been used as an instrument for state power or late-capitalism in its deployment of social discipline, military warfare and what Debord referred to as the 'society of the spectacle' in his 1967 book. The notion that art, or 'the spectacle' of art, is a technique of control within political machinations is certainly not a new one. As Agamben writes, 'Confronted with phenomena such as the power of the society of the spectacle that is everywhere transforming the political realm today, is it legitimate or even possible to hold subjective technologies and political techniques apart?' (1995: 6) Today, from Hollywood's catastrophe-as-spectacle, to the saturation of violence through photographic and media testimony on the living-room television, we are increasingly compelled rather than repelled by the aesthetics of violence.

The stillness of the image caught in the explosive moment, or the emphasis of a bullet's motion and destruction, creates a temporal expansion and spatial intensification of the instant. This clearly has its antecedents within the history of photography, with Mach and 
Edgerton being just two examples. And yet we might propose that Gersht also references and reflects upon that history within his work, inherently critiquing the very processes he uses, self-reflexively drawing upon 'the technological sublime' that both seduces and violates. In doing so, the work might accord with a Heideggerian notion that art provides the means to challenge technological modernity by providing the 'essential reflection upon technology and decisive confrontation with it' ([1953] 2003: 264). Art is itself a technology, but simultaneously fundamentally different since it provides a position from which to critique its own status as techne. Art therefore contains the possibility of revealing the crisis unfolding in technology.

This crisis is woven throughout photographic history in its status as a modern medium. Its technique for documenting and classifying the human subject has undergone great refinement since the nineteenth century, and its role as an instrument of control has greatly expanded. From Nadar's aerial views of Paris in the mid-nineteenth century, visual technologies are now concerned with instantaneous information on a global scale through satellite placements. There is a clear technological and panoptical advancement from the camera's nineteenth-century biopolitical instrumentation in recording individuals, the twentieth-century observation of society and behaviour, to what Virilio describes now as the fullest realization of 'truly panoptical vision' ([1999] 2000: 19) in the twenty-first century through 'finding, tracking and targeting virtually in real time any significant element moving on the surface of the earth' ([1999] 2000,18). The history of photography's revelation of the unseen has a complex interrelation of science, art and politics. These forces, in different ways, motivate the very question concerning the development and deployment of technology. Beauty, spectacle, control and destruction overlap, unfold and envelop each other, but are all manifested through photography's technological form.

\section{References}

Adelman, L. and Compton, M. (1980), 'Mathematics in early abstract art', in M. Compton (ed), Towards a New Art: Essays on the Background to Abstract Art 1910-1920, London: Tate Gallery, pp. $64-89$. 
Agamben, G. (1995), Homo Sacer: Sovereign Power and Bare Life (trans. D. Heller-Roazen), Stanford, CA: Stanford University Press.

Armstrong, T. (1998), Modernism, Technology and the Body: A Cultural Study, Cambridge: Cambridge University Press.

Batchen, G. ([1997] 1999), Burning with Desire: The Conception of Photography, Cambridge, MA and London: MIT Press.

Bate, D. (2010), 'The memory of photography', Photographies, 3:2, pp. 243-57.

Benjamin, W. ([1936] 1977), 'The storyteller', in H. Arendt (ed.), Illuminations (trans. H. Zohn), London: Fontana, p. 84.

Berghaus, G. (1995), Marinetti Early Career and Wrings 1899-1909, Leeds: W.S. Maney \& Son.

Crary, J. (1990), Techniques of the Observer: On Vision and Modernity in the Nineteenth Century, Cambridge and London: MIT Press.

Debord, G. ([1967] 2004), The Society of the Spectacle (trans. K. Knabb), London: Rebel Press.

Foucault, M. ([1966] 2007), The Order of Things, London and New York: Routledge.

([1976] 1990), The History of Sexuality: Volume I An Introduction (trans. R. Hurley), Middlesex: Penguin. 
Gage, J. (1980), 'The psychological background to early modern colour: Kandinsky, Delaunay and Mondrian', in Towards a New Art: Essays on the Background to Abstract Art 1910-1920, in M. Compton (ed), London: The Tate Gallery, pp. $22-40$.

Gersht, O. (2007), 'Inaugural professorial lecture', University for the Creative Arts, Rochester, Kent, 6 December.

(2007-08), 'Exploding flowers \& other matters', Exit, 'Flowers' no. 28, NovemberJanuary, http://www.exitmedia.net/prueba/eng/articulo.php?id=228. Accessed 01/01/2008.

Heidegger, M. ([1953] 2003), 'The question concerning technology', in R. Scharff and V. Dusek (eds), Philosophy of Technology: The Technological Condition, An Anthology, Malden, MA; Oxford: Blackwell, pp. $252-264$.

Henderson, Linda D. (1983), The Fourth Dimension and Non-Euclidean Geometry in Modern Art, Princeton, NJ: Princeton University Press.

Husserl, E. ([1936] 1989), Origin of Geometry (trans. John P. Leavey Jr.), Lincoln and London: University of Nebraksa Press.

Kracauer, S. ([1927a] 1993), 'Photography', Critical Enquiry, 19:3, Spring, pp. 421 - 436.

([1927b] 1995), 'The mass ornament', in T. Y. Levin (ed.), The Mass Ornament: Weimar Essays (trans. T. Y. Levin), Cambridge, MA: Harvard University Press, pp. 75 - 88.

Lista, G. (2001), Futurism and Photography, London: Merrell.

Lowry, J. (2002), 'Documents of history, allegories of time', in Ori Gersht: Afterglow, London and Tel Aviv: August and Tel Aviv Museum of Art, pp. $153-166$. 
Lyotard, J.-F. ([1988] 1991), The Inhuman, London: Polity Press.

Mach, E. ([1882] 1968), 'The economical nature of physical enquiry', in J. Kockelmans (ed.), Philosophy of Science: The Historical Background, New York and London: The Free Press and Collier-Macmillan, pp. $174-187$.

Marcuse, H. (1964), One Dimensional Man: Studies in the Ideology of Advanced Industrial Society, London: Routledge \& Kegan Paul Ltd.

Marinetti, F. T. and Palazzeschi, A. (1978), Carteggio con un appendice di altre lettere a Palazzeschi (ed. Paolo Prestigiacomo), Milano: Mondadori.

Marschall, L. (1988), The Supernova Story, New Jersey: Princeton University Press.

Stein, G. (1970), Gertrude Stein on Picasso (ed. E. Burns), New York: Liverwright.

Tagg, J. ([1984] 1988), The Burden of Representation: Essays on Photographies and Histories, London: Macmillan.

Virilio, P. ([1984] 1989), War and Cinema: The Logistics of Perception (trans. P. Camiller), London and Brooklyn: Verso.

([1999] 2000), Strategies of Deception (trans. C. Turner), London and New York: Verso.

\section{Contributor details}

Tom Slevin is course leader in Photography at Southampton Solent University. He has published the book Visions of the Human: Art, World War I and the Modernist Subject (I. B. Tauris, 2015). Journal publications have featured in Angelaki: A Journal of the Theoretical 
Humanities, Fashion Theory: Journal of Dress, Body, and Culture, Film International: Journal of World Cinema, Body and Society and Philosophy of Photography.

Contact:

School of Art, Design \& Fashion

Southampton Solent University

East Park Terrace

Southampton

Hampshire

SO14 OYN

E-mail: tom.slevin@solent.ac.uk 